\title{
Olfactory Receptor Neuron Dysfunction in Schizophrenia
}

\author{
Bruce I Turetsky*, I,2, Chang-Gyu Hahn', Steven E Arnold' and Paul J Moberg',2 \\ 'Neuropsychiatry Division, Department of Psychiatry, University of Pennsylvania, Philadelphia, PA, USA; ${ }^{2}$ Smell and Taste Center, Department of \\ Otorhinolaryngology_ _ Head and Neck Surgery, University of Pennsylvania, Philadelphia, PA, USA
}

\begin{abstract}
Olfactory impairments are a common feature of schizophrenia. Impairments in odor detection and odor identification are present early in the course of illness and among those at risk for the disorder. These behavioral impairments have been linked to both physiological and anatomical abnormalities in the neural substrates subserving olfaction, including relatively peripheral elements of the olfactory system. The location of olfactory receptor neurons in the nasal epithelium allows noninvasive access to these neurons in living subjects. This offers a unique opportunity to directly assess neuronal integrity in vivo in patients. The peripheral olfactory receptor neuron response to odor stimulation was assessed in 21 schizophrenia patients and 18 healthy comparison subjects. The electroolfactogram, representing the electrical depolarization of the olfactory receptor neurons, was recording following stimulation with different doses and durations of hydrogen sulfide, a pure olfactory nerve stimulant. Schizophrenia patients had abnormally large depolarization responses following odor stimulation, independent of clinical symptomatology, antipsychotic medication dosage or smoking history. Although the precise pathophysiological mechanism is unknown, this olfactory receptor neuron abnormality is consistent with several lines of evidence suggesting altered proliferation or maturation of olfactory receptor neuron cell lineages in schizophrenia. It is also consistent with emerging evidence of disruptions of cyclic AMP-mediated intracellular signaling mechanisms, and may be a marker of these disruptions. It unambiguously demonstrates that neurophysiological disturbances in schizophrenia are not limited to cortical and subcortical structures, but rather include even the most peripheral sensory neurons.

Neuropsychopharmacology (2009) 34, 767-774; doi:I0.1038/npp.2008.139; published online 27 August 2008
\end{abstract}

Keywords: schizophrenia; olfaction; olfactory receptor neuron; olfactory epithelium; electroolfactogram; signal transduction

\section{INTRODUCTION}

There is increasing evidence that olfactory impairments are a common feature of schizophrenia (Moberg et al, 1999). This is not unexpected, because olfactory processing is mediated by many of the same brain areas implicated in the illness, including the ventromedial temporal lobe, basal forebrain, prefrontal cortex, and diencephalon. The olfactory system thus shares a common neural substrate with many of the cognitive and emotion processes that are abnormal in schizophrenia. Behavioral studies have demonstrated impairments in odor detection threshold sensitivity (ie ability to detect the presence of low concentrations of an odorant), as well as odor identification and odor recognition memory. These deficits are present early in the course of illness and, among individuals at high risk for the disorder, they may help to identify those who will eventually develop the full clinical syndrome (Brewer et al, 2003). Although olfactory deficits may progress over time (Moberg

\footnotetext{
*Correspondence: Dr BI Turetsky, Neuropsychiatry Division, Department of Psychiatry, University of Pennsylvania, IOth Floor, Gates Building, 3400 Spruce Street, Philadelphia, PA 19104, USA, Tel: + I 215615 3607, Fax: + I 2156627903 ,

E-mail: turetsky@bbl.med.upenn.edu

Received 12 June 2008; revised 4 August 2008; accepted 5 August 2008
}

et al, 1997), they are not explained by symptom severity, antipsychotic medication use, or increased smoking among patients (Moberg et al, 1999).

These behavioral impairments in olfactory function have now been linked to specific physiological and anatomical abnormalities in the neural substrates subserving olfaction. Chemosensory evoked potential responses originating in the primary olfactory cortex and the gray matter volume of this cortical region are both decreased in schizophrenia patients (Turetsky et al, 2003b,c). There is also evidence indicating that these abnormalities extend to more peripheral elements of the olfactory system. MRI scans of the olfactory bulbs have demonstrated reduced bulb volumes in both schizophrenia patients (Turetsky et al, 2000) and their unaffected first-degree relatives (Turetsky et al, 2003a), suggesting a genetically mediated abnormality. Histological examination of olfactory epithelial tissue, obtained postmortem from schizophrenia patients, has documented the presence of increased numbers of immature olfactory receptor neurons (ORNs; Arnold et al, 2001), consistent with disrupted growth and development of these primary sensory neurons.

The location of ORNs in the posterior-superior aspect of the nasal cavity allows direct noninvasive access to these neurons in living subjects. This offers the unique opportunity to directly assess the functional integrity of a specific 
neural substrate, in vivo. In this study, we examined the electroolfactogram (EOG) response in schizophrenia patients and healthy comparison subjects. The EOG represents the membrane depolarization of ORNs in response to a chemosensory odorant stimulus. By recording this depolarization response directly from the nasal mucosa, we were able to examine the physiological responsiveness of these peripheral sensory neurons, independent of such factors as subject cooperation, attentiveness, and cognitive ability that typically confound other in vivo methods in schizophrenia research. Given the histological evidence of neurodevelopmental dysregulation, we hypothesized that the physiological responses of the neurons would also be abnormal.

\section{MATERIALS AND METHODS}

This investigation was conducted in accordance with the Declaration of Helsinki Principles. All experimental procedures were approved by the University of Pennsylvania Institutional Review Board. Written informed consent was obtained from each subject before the study.

\section{Subjects}

The sample included 21 patients with a DSM-IV diagnosis of schizophrenia (14 men, 7 women) and 18 healthy comparison subjects (11 men, 7 women). Patients were recruited from the outpatient psychiatric facilities at the Hospital of the University of Pennsylvania and through outreach at Community Mental Health Centers and family support programs. All patients were stable outpatients at the time of testing. Healthy comparison subjects were recruited through advertisements in community newspapers and neighborhood bulletin boards.

All subjects received a semi-structured psychiatric interview (Diagnostic Interview for Genetic Studies; Nurnberger et al, 1994) and the Family Interview for Genetic Studies (Maxwell, 1992). The patients were rated on the Brief Psychiatric Rating Scale (BPRS; Overall and Gorham, 1962), the Scale for Assessment of Negative Symptoms (SANS; Andreasen, 1983), and Scale for Assessment of Positive Symptoms (SAPS; Andreasen, 1984). Ratings were completed by investigators trained to a criterion reliability of 0.90 (intraclass correlation). Patients were excluded for any concurrent Axis I diagnosis other than schizophrenia. Healthy comparison subjects were excluded for any history of an Axis I diagnosis, Axis II Cluster A (schizotypal, schizoid, or paranoid) personality disorder, or family history of an Axis I psychotic disorder. Across groups, subjects were excluded for any history of a neurological disorder, including head trauma with loss of consciousness, any lifetime history of substance dependence, history of substance abuse within the preceding 6 months, or any medical condition that might affect cerebral functioning. Subjects were also excluded for any obvious craniofacial trauma or abnormality, including septal deviation, and for any acute respiratory condition, cold, or allergy.

There were no differences in either age $(t(38)=0.12$, $p=0.90)$ or gender composition $\left(\chi^{2}(1)=0.13, p=0.72\right)$ between the two groups. Mean age of patients was $37.6 \pm 9.7$ years; mean age of control subjects was $37.2 \pm 10.3$ years.
There were also no significant differences in smoking status, although there was a trend towards greater smoking among patients. Eight patients were active smokers and thirteen were nonsmokers; three controls were smokers, and fifteen were nonsmokers $\left(\chi^{2}(1)=2.20, p=0.14\right)$. Mean cigarette packs per day was $0.35 \pm 0.56$ for patients and $0.08 \pm 0.19$ for controls $(t(38)=1.95, p=0.06)$. Cumulative pack-years of tobacco exposure was $6.93 \pm 14.39$ for patients and $1.22 \pm 3.17$ for controls $(t(38)=1.65, p=0.11)$.

Nineteen of twenty-one patients were medicated at the time of testing. Of these, 8 were taking typical antipsychotics, either alone or in combination with a low-dose atypical; 11 were taking solely atypical antipsychotic medications. Mean daily antipsychotic dosage, calculated as chlorpromazine equivalents, was $332 \pm 305 \mathrm{mg}$. Mean age of illness onset was $20.2 \pm 5.5$ years and mean illness duration was $17.4 \pm 9.7$ years. Mean total BPRS score for 18 items was $30.6 \pm 9.4$. This indicates a very mild level of acute symptomatology.

\section{Experimental Procedures}

Olfactory stimulation. Odor stimuli were presented by a dynamic multi-odorant air dilution olfactometer (OM4/B; Heinrich Burghart GmbH, Wedel, Germany). This computer-controlled apparatus allows for precisely timed pulses of odorants to be embedded in a constantly flowing air stream with specified temperature and humidity $\left(36.5^{\circ} \mathrm{C} ; 80 \%\right.$ relative humidity) without transient pressure artifacts. A continuous airstream is delivered to one nasal chamber by a $6 \mathrm{~cm}$ long Teflon ${ }^{\mathrm{TM}}$ tube with a $4 \mathrm{~mm}$ outer diameter inserted approximately $1 \mathrm{~cm}$ into one naris. This airstream is then replaced by one of several odorized airstreams for time periods ranging as low as $50 \mathrm{~ms}$, using a nonelectrical vacuum switching device, which allows for the switching of the airstreams without pressure or thermal artifacts. By carefully tuning the switching of the vacuums, the stimulus characteristics can be optimized so that the rise time of the stimulus does not exceed $20 \mathrm{~ms}$. This guarantees that the subject has no additional cues, such as tactile or thermal sensations, which could provide extraneous information about the timing of stimulus presentation. Also, to eliminate any possible auditory cues associated with the opening and closing of the valves, subjects listened to $65 \mathrm{~dB}$ continuous white noise presented through insert ear phones.

Hydrogen sulfide $\left(\mathrm{H}_{2} \mathrm{~S}\right)$ was used as the stimulant for the study. Unlike some odorants, which are also astringent, $\mathrm{H}_{2} \mathrm{~S}$ is a pure olfactory nerve stimulant that does not induce any significant coincidental somatosensory nerve activity. Two different concentrations of $\mathrm{H}_{2} \mathrm{~S}(17.6,8.8 \mathrm{ppm})$ were presented at each of four different stimulus durations $(100,500,1000,2000 \mathrm{~ms})$. Interstimulus interval was $7.5 \pm 2.5 \mathrm{~s}$. At each stimulus duration and concentration, 5-10 odor pulses were presented to each nostril to ensure a representative sampling of the EOG response. The order of nostril and stimulus presentation was randomized across subjects. Subjects were asked to sit quietly in a relaxed awake state and to breathe through the mouth. They were not alerted before stimulus presentation and were not required to respond in any way. 


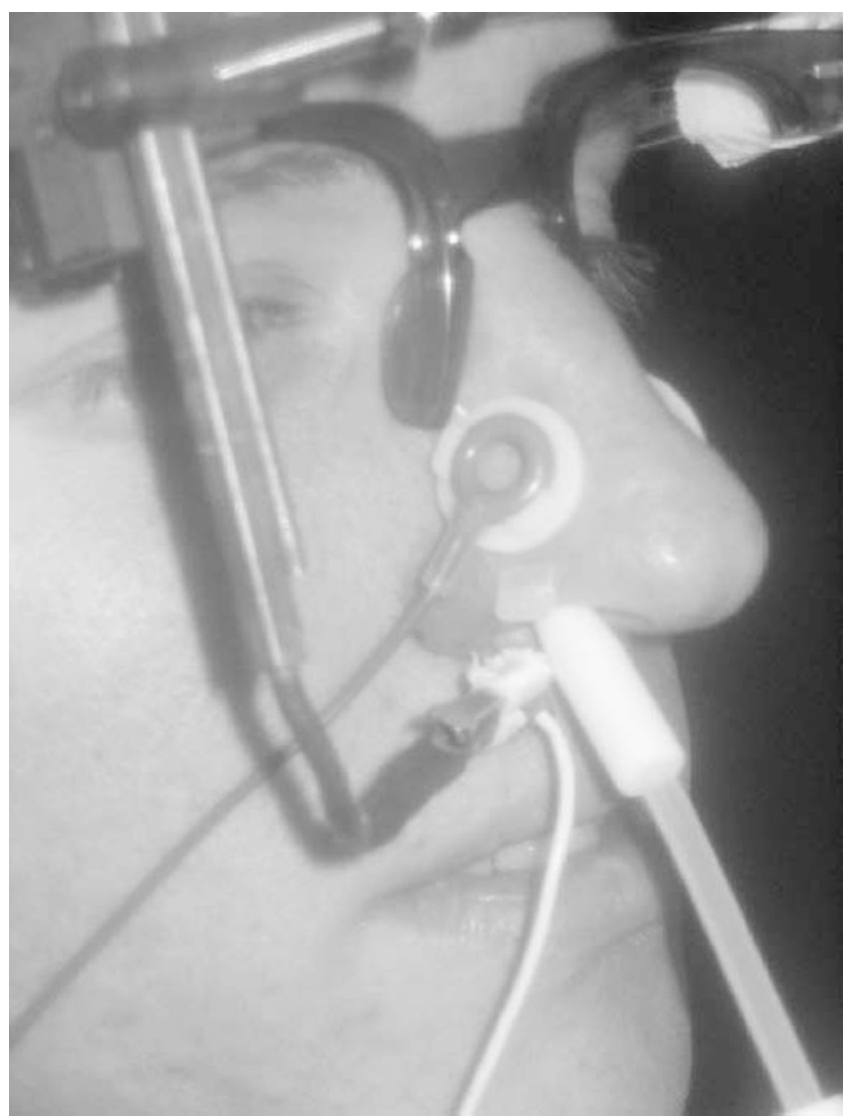

Figure I Experimental setup for recording EOG. Odorant is delivered through the large plastic nasal cannula. Wire recording electrode is inserted into the nasal cavity and held in position on the epithelial surface by an adjustable clip mechanism attached to a pair of glasses that are strapped to the head. Circular reference electrode is placed on the external lateral surface of the nose.

EOG recording and data processing. A thin sintered silversilver chloride wire electrode $(0.4 \times 8.0 \mathrm{~mm}$; In vivo Metric, Healdsburg, CA) was coated with electrode gel and inserted into the nasal cavity. Under endoscopic guidance, the recording end of the electrode was placed on the posterior superior aspect of the medial surface of the middle turbinate. This is the site that we routinely target for nasal epithelial biopsies, from which we successfully harvest ORNs (Hahn et al, 2005). A reference electrode was placed on the external lateral surface of the contralateral nasal cavity and a ground electrode was placed on the forehead. Figure 1 demonstrates the experimental setup for odor stimulus delivery and EOG response recording. Electrical potentials were amplified with an AC-coupled Neuroscan Synamps amplifier (gain: 1000; range: $5.5 \mathrm{mV}$; resolution: $0.084 \mu \mathrm{V}$; bandpass filter settings: $0.10-50.0 \mathrm{~Hz}$ ). Data were digitally sampled at $250 \mathrm{~Hz}$ and written to disk for offline postprocessing. A $2000 \mathrm{~ms}, 17.6 \mathrm{ppm}$ odorant test pulse was delivered first to ensure that a robust EOG response was elicited, and the recording electrode was repositioned, when necessary, to improve the quality of the recording before the start of data acquisition.

Figure 2 illustrates the morphology of the EOG response following presentation of a single $1000 \mathrm{~ms}$ puff of $\mathrm{H}_{2} \mathrm{~S}$, at different concentrations, in an individual subject. There is a

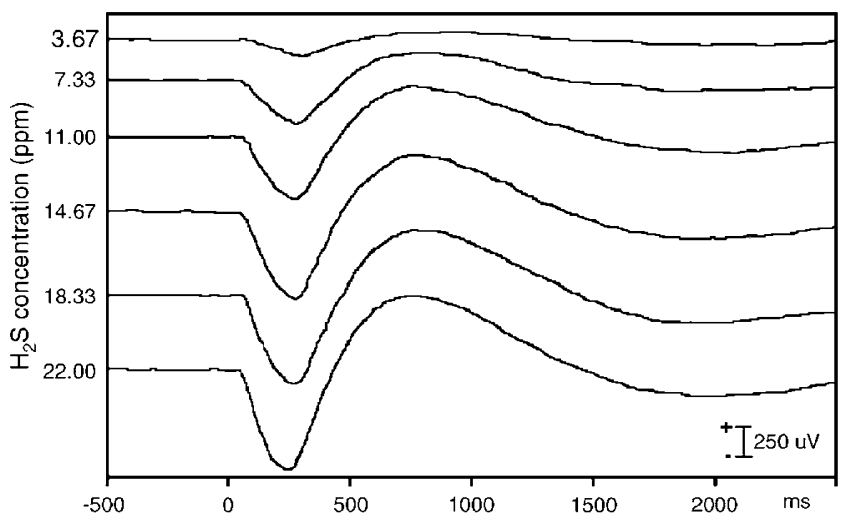

Figure 2 Morphology of the EOG following presentation of a single 1000 ms puff of $\mathrm{H}_{2} \mathrm{~S}$, at different concentrations, in an individual subject. This response illustrates the typical dose-dependent depolarization of the olfactory receptor neurons.

characteristic depolarization that reaches its maximum at $\sim 300 \mathrm{~ms}$, followed by repolarization. The subsequent overshoot and slow return to baseline reflect the low frequency response characteristics of the AC-coupled amplifiers. The initial negative voltage change is highly dependent on the concentration of the odorant, as expected for the EOG originating in ORNs. The absence of an observable response independent of odor concentration confirms that there was no significant somatosensory stimulation or other nonspecific response artifact associated with the odor presentation. The latency and amplitude of the maximum depolarization was measured for each individual EOG waveform, and mean values were computed for each subject for each combination of odor concentration and duration.

\section{Statistical Analysis}

Multivariate analysis of variance was used to assess patientcontrol differences, with diagnosis and smoking status (smoker/nonsmoker) as between-subjects factors, nostril, $\mathrm{H}_{2} \mathrm{~S}$ concentration and stimulus duration as within-subject factors, and age as a covariate. As normal aging has a significant effect on olfactory abilities (Doty et al, 1984), it may be important to account for the impact of this measure on the observed intersubject variance, even when the diagnostic groups do not differ (Miller and Chapman, 2001). Dependent measures, in separate analyses, were mean amplitude and latency of the EOG depolarization response (see Table 1). Significant $(p<0.05)$ multivariate interactions were dissected by post hoc univariate contrasts of patient $v s$ control responses to each individual class of stimuli having a fixed odor concentration and duration.

\section{RESULTS}

\section{EOG Amplitude}

There was a significant two-way interaction of diagnosis $\times$ odor duration $(\mathrm{F}(3102)=2.72, p=0.049)$ and a threeway interaction of diagnosis $\times$ odor concentration $\times$ odor duration $(\mathrm{F}(3102)=3.94, p=0.011)$. As shown in Figure 3, patients had larger EOG amplitudes across all experimental 
Table I Electroolfactogram Response (mean \pm SD)

\begin{tabular}{|c|c|c|c|c|}
\hline & \multicolumn{2}{|c|}{$\begin{array}{l}\text { Odor concentration: } \\
8.8 \mathrm{ppm}\end{array}$} & \multicolumn{2}{|c|}{$\begin{array}{c}\text { Odor concentration: } \\
\text { I } 7.6 \mathrm{ppm}\end{array}$} \\
\hline & $\begin{array}{c}\text { Amplitude } \\
(\mu \mathrm{V})\end{array}$ & $\begin{array}{l}\text { Latency } \\
(\mathrm{ms})\end{array}$ & $\begin{array}{c}\text { Amplitude } \\
(\mu \mathrm{V})\end{array}$ & $\begin{array}{c}\text { Latency } \\
(\mathrm{ms})\end{array}$ \\
\hline \multicolumn{5}{|c|}{100 ms duration } \\
\hline Patients & $165 \pm 85$ & $225 \pm 75$ & $387 \pm 297$ & $214 \pm 69$ \\
\hline Controls & $129 \pm 72$ & $233 \pm 95$ & $267 \pm 175$ & $209 \pm 67$ \\
\hline \multicolumn{5}{|c|}{500 ms duration } \\
\hline Patients & $310 \pm 175$ & $449 \pm 165$ & $650 \pm 478$ & $400 \pm 158$ \\
\hline Controls & $242 \pm 165$ & $421 \pm 149$ & $406 \pm 257$ & $417 \pm 154$ \\
\hline \multicolumn{5}{|c|}{1000 ms duration } \\
\hline Patients & $305 \pm|7|$ & $497 \pm 223$ & $680 \pm 475$ & $413 \pm 153$ \\
\hline Controls & $248 \pm 168$ & $502 \pm 286$ & $389 \pm 228$ & $426 \pm 167$ \\
\hline \multicolumn{5}{|c|}{2000 ms duration } \\
\hline Patients & $295 \pm 156$ & $523 \pm 163$ & $738 \pm 446$ & $432 \pm 160$ \\
\hline Controls & $282 \pm 202$ & $625 \pm 480$ & $431 \pm 268$ & $549 \pm 368$ \\
\hline
\end{tabular}

conditions, but this group difference was amplified when the odorant was presented either at higher concentration or for longer duration - ie, when the olfactory epithelium was exposed to more odorant molecules. Figure 4 presents the grand average EOG responses for patients and healthy comparison subjects, as well as the median single subject responses, which clearly illustrate this group difference. There was also a two-way interaction of diagnosis $\times$ nostril $(\mathrm{F}(1,34)=5.04, p=0.031)$. Although the mean patient response was greater for both left and right nostril recordings, this group difference was significantly larger when the odorant was presented to the right nostril. There were no associations within the patient group between mean EOG amplitude and any clinical measures, including scores on BPRS, SANS, SAPS, or GAF rating scales, age of illness onset, illness duration, daily medication dosage or smoking status. In particular, there were no significant differences in the EOG responses of the 8 patients who smoked and the 13 who did not. Nor were there any differences in the responses of the eight patients taking typical antipsychotic medications.

\section{EOG Latency}

There was a main effect of odor duration $(\mathrm{F}(3102)=2.93$, $p=0.037$ ) on EOG latency, but no other significant effects. The peak EOG response was delayed following more prolonged odor stimulation, but this was independent of diagnosis.

\section{DISCUSSION}

The results of this study demonstrate that schizophrenia patients produce abnormally large EOG responses following
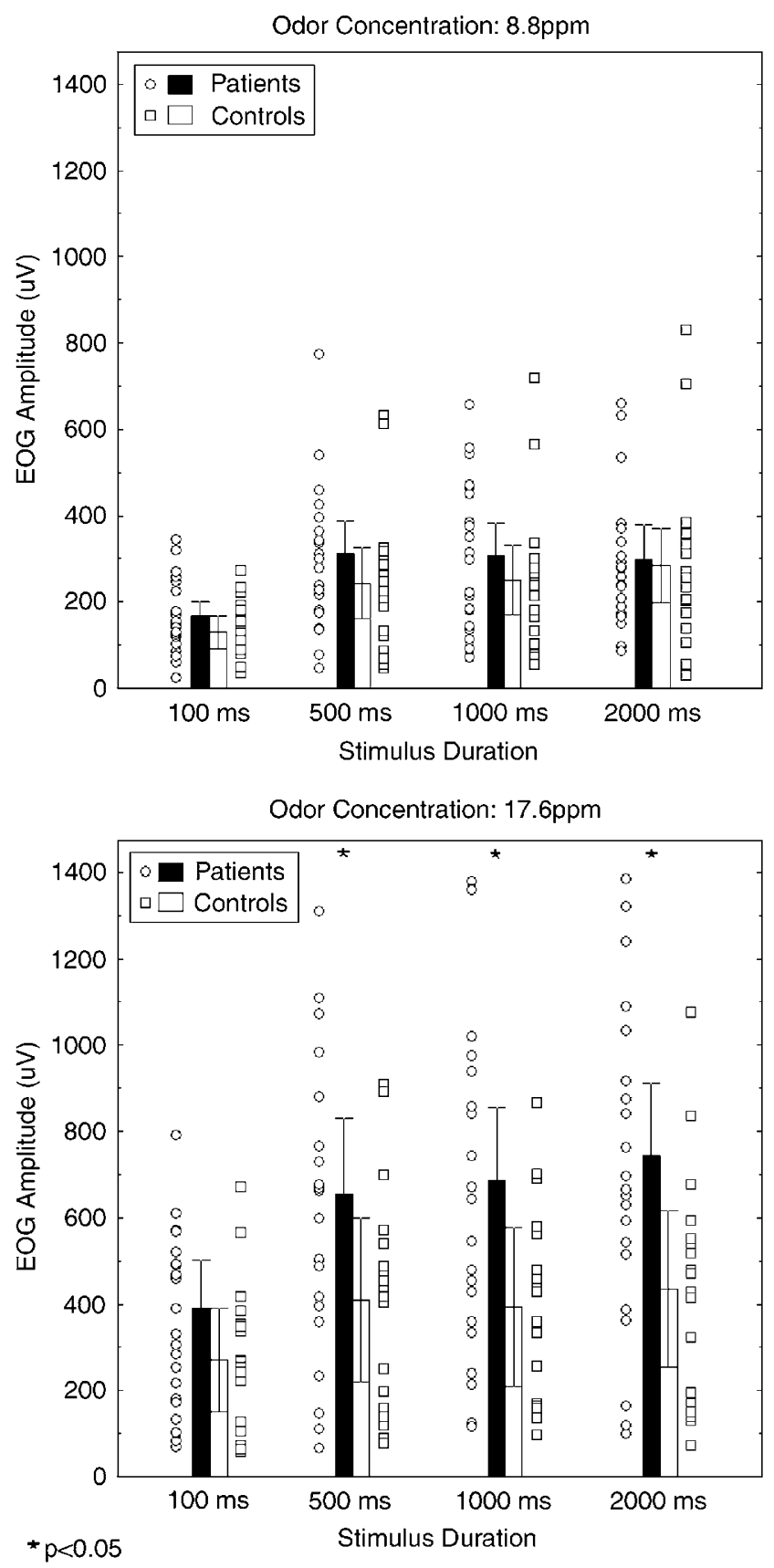

Figure 3 EOG amplitudes for two $\mathrm{H}_{2} \mathrm{~S}$ concentrations across four different stimulus duration conditions in both patients and healthy comparison subjects. Bar plots indicate mean \pm SE. Scatterplots present individual subject responses.

$\mathrm{H}_{2} \mathrm{~S}$ stimulation, which are unrelated to acute symptomatology, antipsychotic medication dosage or smoking history. This suggests that disruptions of neural physiology in schizophrenia are not limited to the cortex and subcortical limbic structures, but rather include even the most peripheral sensory neurons. It is thus consistent with an increasing number of reports of abnormalities in primary sensory areas of the cortex (Sweet et al, 2007; Turetsky et al, $2003 \mathrm{~b}, \mathrm{c}$ ) and suggests that the pathological processes of schizophrenia are more ubiquitous than cognition-based models of hypofrontality (Snitz et al, 2005) or frontaltemporal dysregulation (Weiss et al, 2006) might imply. 

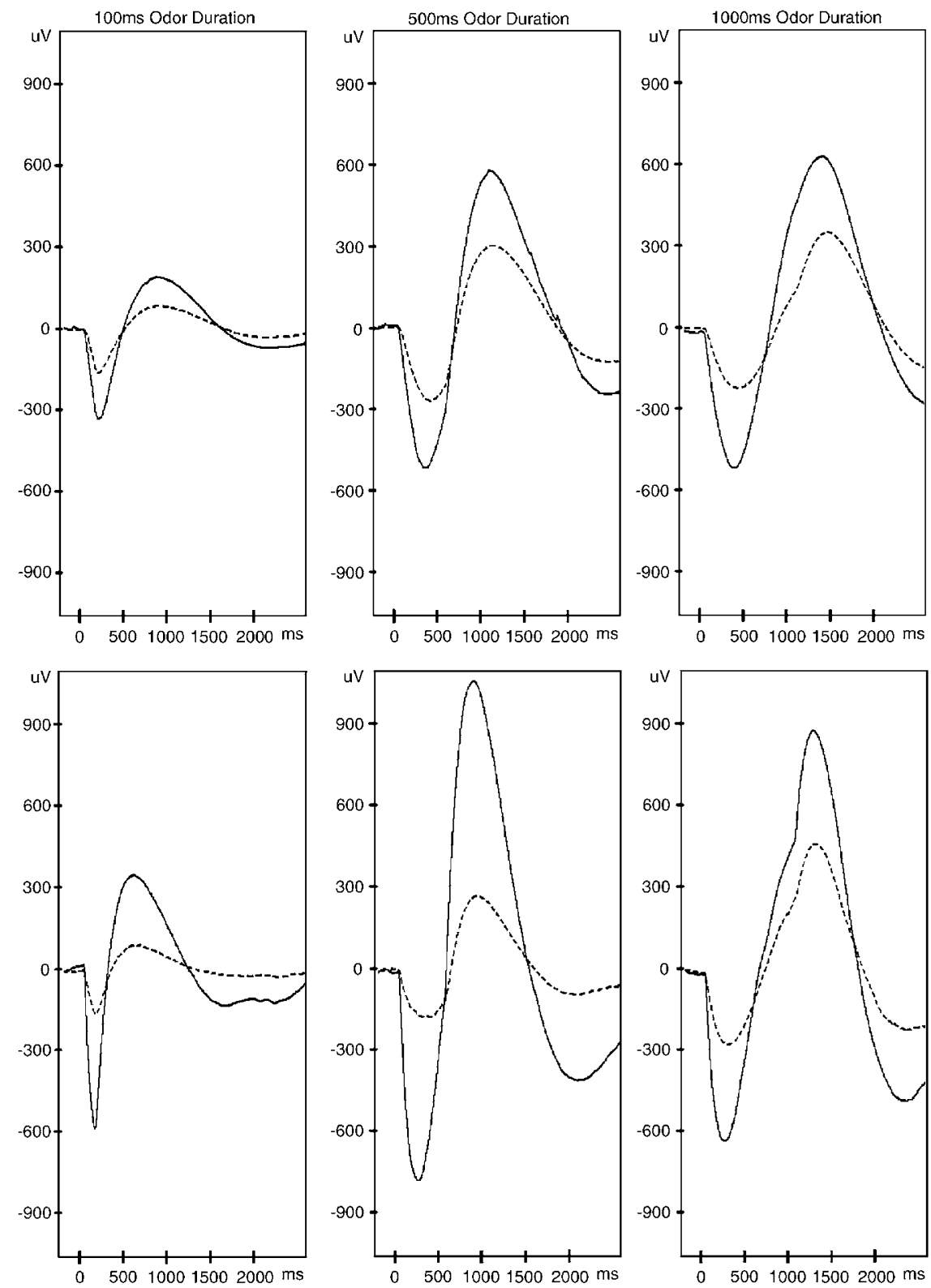

Figure 4 Top: Grand average EOG responses for patients and healthy comparison subjects for I00, 500, and I000 ms presentations of I7.6 ppm $\mathrm{H}_{2} \mathrm{~S}$. Bottom: Representative subject data from the individual patient and healthy comparison subject exhibiting the median response amplitude within their respective groups.

Two aspects of the data require specific comment. First, as indicated in Figure 3, there was a large degree of intersubject variability in EOG responses. This is consistent with in vitro findings of large response variability even at the cellular level. For example, among a group of 329 ORNs, all of which exhibited active responses to the odorant cineole, the magnitudes of responses following exposure ranged from 9 to $724 \mathrm{pA}$ (mean $\pm \mathrm{SD}=215 \pm 163 \mathrm{pA}$; Takeuchi et al, 2003). However, this may also reflect, to some extent, differences in placement of the recording electrode on the olfactory epithelium. ORNs are scattered throughout the epithelium in a diffuse and patchy manner, and there are inevitably some between-subject differences in the proximity of the EOG electrode to the olfactory neurons. As comparable variability was seen in the responses of both patients and controls, it is unlikely that this would reflect any sort of systematic bias across the diagnostic groups.

Second, although lateralized cerebral findings are commonplace in schizophrenia research, it is surprising to see such lateralized effects extend to the level of primary sensory receptors. However, it is well known that the right hemisphere is better adapted to processing olfactory inputs than the left (Doty et al, 1997). We previously observed a similar lateralized right-sided abnormality when we assessed olfactory bulb volumes in unaffected first-degree relatives of schizophrenia patients (Turetsky et al, 2003a). Other studies have demonstrated larger right olfactory bulbs, as a consequence of normal development, in diverse species (Heine and Galaburda, 1986; Prasada Rao and Finger, 1984). There is also evidence that the two bulbs 
contain different levels of modulating neurotransmitters and enzymes (Dluzen and Kreutzberg, 1996; RodriguezGomez et al, 2000). If the right and left olfactory bulbs, which are the axonal targets for the peripheral ORNs, are structurally and functionally distinct then the dysregulation that gives rise to elevated ORN responses in patients could also be one that is manifested primarily on the right side. If this is the case, then an understanding of the normal structural and functional asymmetry of the peripheral olfactory system could provide an important clue to the etiology of this abnormality in schizophrenia.

At this point, though, the pathophysiological mechanisms that might underlie this abnormality are not entirely clear. There appear to be at least three different possibilities: (1) the absolute number of olfactory neurons is greater in schizophrenia patients, hence the observed EOG response is more robust; (2) there is a loss of specificity of olfactory receptor expression in schizophrenia, such that the number of neurons that respond to a particular odorant is increased even if the absolute number of neurons is not; (3) the magnitude of the membrane depolarization current of individual ORNs is increased, so that the recorded EOG response is greater even if the number of responding neurons is unchanged. These alternative mechanisms should not be considered mutually exclusive and there is, in fact, some indirect evidence to support each of them.

With regard to the total number of olfactory neurons, Arnold et al (2001) reported that olfactory epithelial tissue obtained at autopsy from schizophrenia patients had increased numbers of immature GAP43 + neurons relative to p75NGFR + precursor stem cells, compared to epithelial tissue obtained from healthy individuals. Similarly, cultures of olfactory neuroepithelial tissue biopsied from living schizophrenia patients exhibited increased mitosis and greater cell proliferation than olfactory tissue cultures derived from healthy subjects (Féron et al, 1999; McCurdy et al, 2006). Finally, gene expression profiling of olfactory epithelial tissue found increased expression of multiple genes related to cell proliferation, differentiation and neurogenesis in schizophrenia (McCurdy et al, 2006). Collectively, these findings indicate that there is increased neuronal proliferation associated with dysregulated olfactory receptor development in schizophrenia. The observation of increased EOG amplitude is consistent with, and may be a marker of, this increased cell proliferation.

This process may also be exacerbated by a loss of selectivity of olfactory neurons. Normally, a given olfactory neuron expresses only one olfactory receptor on its membrane surface, restricting its response to a specific odorant molecule configuration (Ronnett and Moon, 2002). There is evidence, however, that such selectivity can be altered, as in the case of the alteration of olfactory function with normal human aging (Rawson et al, 1998). Perhaps more importantly, electrophysiological studies of olfactory development also indicate that the olfactory epithelium of immature animals is highly nonselective, with individual olfactory neurons responding to many different odorants (Gesteland et al, 1982). Selectivity appears to be acquired only later in development. As the basic finding of Arnold et al (2001) was an increased density of immature rather than mature neurons in schizophrenia, it is possible that this would translate into an increased number of neurons that respond nonselectively to $\mathrm{H}_{2} \mathrm{~S}$. Although this is a plausible hypothesis, specific evidence remains lacking.

Another possibility is that the magnitude of the EOG response is increased at the level of the individual neuron - ie, that there are alterations in the intracellular signal transduction pathways that lead to increased membrane depolarization. The binding of an odorant to an olfactory receptor results in increased levels of intracellular cyclic AMP (cAMP). cAMP functions as a second messenger, causing cyclic nucleotide-gated ion channels to open and cations to enter the cell. There is a strong correlation between the magnitude of this transmembrane current, which produces the observed EOG response, and the levels of adenylyl cyclase activation and cAMP accumulation within olfactory neurons (Lowe et al, 1989). There is increasing evidence to suggest that this intracellular signaling cascade may be dysregulated in schizophrenia. An early study, using B lymphocytes, found increased adenylyl cyclase activity and cAMP accumulation in cells from schizophrenia patients following stimulation with forskolin, which binds to a high affinity site on the catalytic subunit of adenylyl cyclase (Natsukari et al, 1997). More recently it has been shown that DISC1, the schizophrenia susceptibility gene located on chromosome 1q42, acts intracellularly to sequester phosphodiesterase, the enzyme responsible for the degradation of cAMP, and to release it in response to elevated levels of cAMP (Millar et al, 2005). Alterations of the quantity or function of the DISC1 protein will therefore necessarily alter the regulation of cAMP levels. Similarly, a polymorphism of the GNAS1 gene on chromosome 20q13, which codes for the $\alpha$-subunit of the $\mathrm{G}$ protein that stimulates adenylyl cyclase, has been associated with deficit syndrome schizophrenia (Minoretti et al, 2006). Alterations of this protein would affect the production, rather than the degradation, of cAMP following stimulation. Alterations in cAMP levels could also be a secondary effect of either glutamatergic (Chetkovich and Sweatt, 1993) or dopaminergic (Neves et al, 2002) dysregulation, both of which have been implicated in schizophrenia pathophysiology. Although these associations support the idea that cAMP signaling is disrupted in schizophrenia, the status of olfactory signal transduction in this disorder has yet to be examined.

We cannot, at this time, delineate the relative contribution of each of these potential mechanisms to the abnormalities we have observed. Any one of these disturbances at the level of the epithelial receptor could, presumably, lead to the olfactory sensory perceptual deficits that are observed in behavioral studies of odor identification and threshold detection sensitivity. Future studies using olfactory epithelial biopsy material are required to clarify the relationship between the electrophysiological and biochemical responses of ORNs. The extent to which these abnormalities generalize to other odorants may also shed light on their underlying mechanisms, because odorants differ substantially in the level of adenylyl cyclase excitation that they produce (Sklar et al, 1986). The extent to which this finding is specific to certain groups of odorants needs to be determined, as does its specificity to schizophrenia. Olfactory neurons from bipolar patients exhibit abnormal responses to odor stimulation in culture (Hahn et al, 2005), but it is not clear if their EOG responses are similar to or 
different from those of schizophrenia patients. The specificity of this finding to schizophrenia, its relationship to observed psychophysical olfactory deficits, and its status in unaffected individuals at genetic risk for the disorder are all questions that have yet to be investigated.

Finally, although we observed no association between EOG amplitude and either the dosage or class (typical vs atypical) of antipsychotic medication, we cannot entirely rule out the possibility that these findings are a consequence of patients' use of antipsychotic medications, which may have altered dopaminergic activity in the nasal mucosa in a manner that is not dose-dependent. Recent in vitro evidence from slice preparations of the mouse olfactory epithelium (Hegg and Lucero, 2004) indicates that exogenous dopamine can decrease the odor-induced responses of ORNs through inhibition of L-type voltage-gated $\mathrm{Ca}^{2+}$ channels. $\mathrm{D}_{2}$ dopamine receptor antagonism can completely reverse this response inhibition and return neuronal excitability to normal. Importantly, though, a $\mathrm{D}_{2}$ receptor antagonist alone does not appear to amplify the odor-induced ORN response. Also, previous studies have demonstrated odor-induced cortical evoked potential abnormalities in schizophrenia patients independent of medication status (Turetsky et al, 2003b), as well as in healthy unmedicated first-degree relatives (Turetsky et al, 2008). Nevertheless, altered mucosal dopaminergic activity in patients, either as a primary dysfunction of the illness or as a secondary response to pharmacological treatment, could have contributed to our findings. It will therefore be very important to determine, in future studies, whether new-onset unmedicated schizophrenia patients, individuals with prodromal symptoms, or unaffected family members exhibit similar EOG abnormalities.

\section{ACKNOWLEDGEMENTS}

We thankfully acknowledge the advice and guidance of $\mathrm{Dr}$ Richard L Doty and Dr Raquel E Gur, and the assistance in data collection of Ms Kiana Owzar, Mr David Roalf, and Mr Charles Glass.

\section{DISCLOSURE/CONFLICT OF INTEREST}

This work was supported by NIH grant MH0599852 awarded to Dr Turetsky. None of the authors have potential conflicts of interest relevant to the subject matter of the article. None of the authors have received, or anticipate receiving, compensation for professional services from any organization other than the University of Pennsylvania.

\section{REFERENCES}

Andreasen NC (1983). The Scale for the Assessment of Negative Symptoms (SANS). The University of Iowa: Iowa City, IA.

Andreasen NC (1984). The Scale for the Assessment of Positive Symptoms (SAPS). The University of Iowa: Iowa City, IA.

Arnold SE, Han LY, Moberg PJ, Turetsky BI, Gur RE, Trojanowski JQ et al (2001). Dysregulation of olfactory receptor neuron lineage in schizophrenia. Arch Gen Psychiatry 58: 829-835.

Brewer WJ, Wood SJ, McGorry PD, Francey SM, Phillips LJ, Yung $\mathrm{AR}$ et al (2003). Impairment of olfactory identification ability in individuals at ultra-high risk for psychosis who later develop schizophrenia. Am J Psychiatry 160: 1790-1794.

Chetkovich DM, Sweatt JD (1993). NMDA receptor activation increases cyclic AMP in area CA1 of the hippocampus via calcium/calmodulin stimulation of adenylyl cyclase. J Neurochem 61: 1933-1942.

Dluzen DE, Kreutzberg JD (1996). Norepinephrine is lateralized within the olfactory bulbs of male mice. J Neurochem 66: 1222-1226.

Doty RL, Bromley SM, Moberg PJ, Hummel T (1997). Laterality in human nasal chemoreception. In: Christman S (ed). Cerebral Asymmetries in Sensory and Perceptual Processing. NorthHolland: Amsterdam. pp 497-542.

Doty RL, Shaman P, Applebaum SL, Giberson R, Siksorski L, Rosenberg L (1984). Smell identification ability: changes with age. Science 226: 1441-1443.

Féron F, Perry C, Hirning MH, McGrath J, Mackay-Sim A (1999). Altered adhesion, proliferation and death in neural cultures from adults with schizophrenia. Schizophr Res 40: 211-218.

Gesteland RC, Yancey RA, Farbman AI (1982). Development of olfactory receptor neuron selectivity in the rat fetus. Neuroscience 7: 3127-3136.

Hahn CG, Gomez G, Restrepo D, Friedman E, Josiassen R, Pribitkin EA et al (2005). Aberrant intracellular calcium signaling in olfactory neurons from patients with bipolar disorder. Am J Psychiatry 162: 616-618.

Hegg CC, Lucero MT (2004). Dopamine reduces odor- and elevated- $\mathrm{K}^{+}$-induced calcium responses in mouse olfactory receptor neurons in situ. J Neurophysiol 91: 1492-1499.

Heine O, Galaburda AM (1986). Olfactory asymmetry in the rat brain. Exp Neurol 91: 392-398.

Lowe G, Nakamura T, Gold GH (1989). Adenylate cyclase mediates olfactory transduction for a wide variety of odorants. Proc Natl Acad Sci USA 86: 5641-5645.

Maxwell ME (1992). Maxwell Family Interview for Genetic Studies (FIGS): A Manual for FIGS. Clinical Neurogenetics Branch Intramural Research Program, National Institute of Mental Health: Bethesda, MD.

McCurdy RD, Féron F, Perry C, Chant DC, McLean D, Matigian N et al (2006). Cell cycle alterations in biopsied olfactory neuroepithelium in schizophrenia and bipolar I disorder using cell culture and gene expression analyses. Schizophr Res 82: 163-173.

Millar JK, Pickard BS, Mackie S, James R, Christie S, Buchanan SR et al (2005). DISC1 and PDE4B are interacting genetic factors in schizophrenia that regulate cAMP signaling. Science 310: 1187-1191.

Miller GA, Chapman JP (2001). Misunderstanding analysis of covariance. J Abnorm Psychol 110: 40-48.

Minoretti P, Politi P, Coen E, Di Vito C, Bertona M, Bianchi M et al (2006). The T393C polymorphism of the GNAS1 gene is associated with deficit schizophrenia in an Italian population sample. Neurosci Lett 397: 159-163.

Moberg PJ, Agrin R, Gur RE, Gur RC, Turetsky BI, Doty RL (1999). Olfactory dysfunction in schizophrenia: a qualitative and quantitative review. Neuropsychopharmacology 21: 325-340.

Moberg PJ, Doty RL, Turetsky BI, Arnold SE, Mahr RN, Gur RC et al (1997). Olfactory identification deficits in schizophrenia: correlation with duration of illness. Am J Psychiatry 154: 1016-1018.

Natsukari N, Kulaga H, Baker I, Wyatt RJ, Masserano JM (1997). Increased cyclic AMP response to forskolin in Epstein-Barr virus-transformed human B-lymphocytes derived from schizophrenics. Psychopharmacology (Berl) 130: 235-241.

Neves SR, Ram PT, Iyengar R (2002). G protein pathways. Science 296: $1636-1639$.

Nurnberger Jr JI, Blehar MC, Kaufmann CA, York-Cooler C, Simpson SG, Harkavy-Friedman J et al (1994). Diagnostic 
Interview for Genetic Studies. Rationale, unique features, and training. NIMH Genetics Initiative. Arch Gen Psychiatry 51: 849-859.

Overall JR, Gorham DR (1962). The Brief Psychiatric Rating Scale. Psychol Rep 10: 799-812.

Prasada Rao PD, Finger TE (1984). Asymmetry of the olfactory system in the brain of the winter flounder, Pseudopleuronectes americanus. J Comp Neurol 225: 492-510.

Rawson NE, Gomez G, Cowart B, Restrepo D (1998). The use of olfactory receptor neurons (ORNs) from biopsies to study changes in aging and neurodegenerative diseases. Ann N Y Acad Sci 855: 701-707.

Rodriguez-Gomez FJ, Rendon-Unceta MC, Sarasquete C, Munoz-Cueto JA (2000). Localization of tyrosine hydroxylaseimmunoreactivity in the brain of the Senegalese sole, Solea senagalensis. J Chem Neuroanat 19: 17-32.

Ronnett GV, Moon C (2002). G proteins and olfactory signal transduction. Annu Rev Physiol 64: 189-222.

Sklar PB, Anholt RR, Snyder SH (1986). The odorant-sensitive adenylate cyclase of olfactory receptor cells. Differential stimulation by distinct classes of odorants. J Biol Chem 261: 15538-15543.

Snitz BE, MacDonald III A, Cohen JD, Cho RY, Becker T, Carter CS (2005). Lateral and medial hypofrontality in first-episode schizophrenia: functional activity in a medication-naive state and effects of short-term atypical antipsychotic treatment. Am J Psychiatry 162: 2322-2329.
Sweet RA, Bergen SE, Sun Z, Marcsisin MJ, Sampson AR, Lewis DA (2007). Anatomical evidence of impaired feedforward auditory processing in schizophrenia. Biol Psychiatry 61: 854-864.

Takeuchi H, Imanaka Y, Hirono J, Kurahashi T (2003). Crossadaptation between olfactory responses induced by two subgroups of odorant molecules. J Gen Physiol 122: 255-264.

Turetsky BI, Kohler CG, Gur RE, Moberg PJ (2008). Olfactory physiological impairment in first-degree relatives of schizophrenia patients. Schizophr Res 102: 220-229.

Turetsky BI, Moberg PJ, Arnold SE, Doty RL, Gur RE (2003a). Low olfactory bulb volume in first-degree relatives of patients with schizophrenia. Am J Psychiatry 160: 703-708. Schizophr Res 102: 220-9.

Turetsky BI, Moberg PJ, Owzar K, Johnson SC, Doty RL, Gur RE (2003b). Physiologic impairment of olfactory stimulus processing in schizophrenia. Biol Psychiatry 53: 403-411.

Turetsky BI, Moberg PJ, Roalf DR, Arnold SE, Gur RE (2003c). Decrements in volume of anterior ventromedial temporal lobe and olfactory dysfunction in schizophrenia. Arch Gen Psychiatry 60: 1193-1200.

Turetsky BI, Moberg PJ, Yousem DM, Doty RL, Arnold SE, Gur RE (2000). Reduced olfactory bulb volume in patients with schizophrenia. Am J Psychiatry 157: 828-830.

Weiss AP, Goff D, Schacter DL, Ditman T, Freudenreich O, Henderson D et al (2006). Fronto-hippocampal function during temporal context monitoring in schizophrenia. Biol Psychiatry 60: $1268-1277$. 